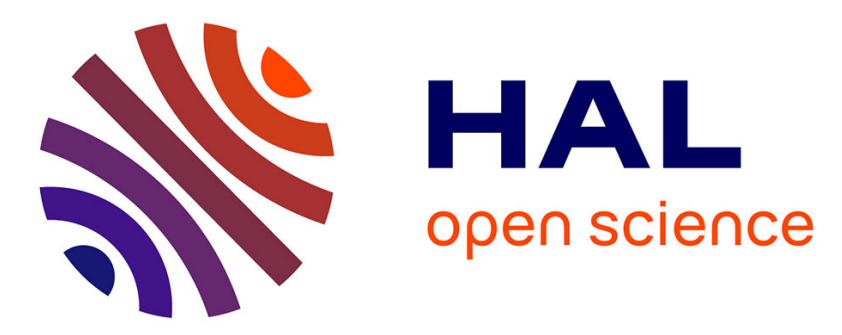

\title{
Evolution of the Lorenz Energy Cycle in the Intertropical Convergence Zone in the South American Sector of the Atlantic Ocean
}

Ligia A da Silva, Prakki Satyamurty

\section{- To cite this version:}

Ligia A da Silva, Prakki Satyamurty. Evolution of the Lorenz Energy Cycle in the Intertropical Convergence Zone in the South American Sector of the Atlantic Ocean. Journal of Climate, 2013, 26, pp.3466-3481. 10.1175/JCLI-D-11-00426.1 . insu-01527471

HAL Id: insu-01527471

https://hal-insu.archives-ouvertes.fr/insu-01527471

Submitted on 24 May 2017

HAL is a multi-disciplinary open access archive for the deposit and dissemination of scientific research documents, whether they are published or not. The documents may come from teaching and research institutions in France or abroad, or from public or private research centers.
L'archive ouverte pluridisciplinaire $\mathbf{H A L}$, est destinée au dépôt et à la diffusion de documents scientifiques de niveau recherche, publiés ou non, émanant des établissements d'enseignement et de recherche français ou étrangers, des laboratoires publics ou privés. 


\title{
Evolution of the Lorenz Energy Cycle in the Intertropical Convergence Zone in the South American Sector of the Atlantic Ocean
}

\author{
Ligia A. DA SiLVA \\ Laboratoire de Physique et Chimie de l'Environnement et de l'Espace (LPC2E), Centre National de Recherches \\ Scientifiques-Université d'Orléans, Orléans, France, and Instituto Nacional de Pesquisas Espaciais, São José dos Campos, Brazil \\ PRAKKI SATYAMURTY \\ Instituto Nacional de Pesquisas Espaciais, São José dos Campos, and Universidade Estadual do Amazonas, Manaus, Brazil
}

(Manuscript received 9 August 2011, in final form 29 November 2012)

\begin{abstract}
The intertropical convergence zone (ITCZ) in the South American sector of the Atlantic Ocean is identified using outgoing longwave radiation (OLR) data in order to investigate the evolution of the Lorenz energy cycle in the region dominated by this large-scale feature. The NCEP reanalysis data are utilized to calculate the zonal and eddy components (denoted by $Z$ and $E$, respectively) of kinetic energy $K$ and available potential energy $A$ (i.e., $K_{Z}, K_{E}, A_{Z}$, and $A_{E}$ ) and their conversions, on a daily basis. A wavelet decomposition of the time series is performed to detect long-term cycles/trends in the Atlantic ITCZ region. This work also investigates trends in sea surface temperature (SST) and sea level pressure (SLP) in the ITCZ region and connections between the ITCZ and the Southern Oscillation index (SOI). A strong annual cycle in all the energy components with high peaks in austral summer is observed. Approximately $91 \%$ of the zonal component of energy is contained on decadal or longer time scales. The annual and semiannual variabilities are significant and the synoptic-scale variability is also present. The zonal component of kinetic energy $K_{Z}$ presents a decreasing trend during the last 28 years, which means a weakening of trade winds in the region studied. The values of $K_{Z}$ and $A_{E}$ are significantly higher during the period $1982 / 83$, indicating that the intense El Niño-Southern Oscillation (ENSO) and/or the El Chichón eruption may have affected the circulation in the ITCZ region. The 28-yr mean energy conversion and generation terms are in general weaker than in the hemispheric calculations but the energy conversions proceed in the same sense as in the hemispheric situation.
\end{abstract}

\section{Introduction}

Observations of the atmospheric and oceanic flow parameters during the last century suggest that Earth's climate is changing on global and regional scales (Meehl et al. 2007; Zhang and Song 2006). The most evident manifestation is the increase of the global surface temperature (Meehl et al. 2007), believed to be caused by the changes in Earth's surface characteristics and the atmospheric composition. To assess the trends in the regional climate it is important and helpful to identify changes in semipermanent atmospheric systems such as the intertropical convergence zone (ITCZ), subtropical

Corresponding author address: Dr. Ligia Alves Da Silva, LPC2E, CNRS-Université d'Orléans, 3A, Avenue de la Recherche Scientifique, Orléans 45071, France.

E-mail: ligia.silva@inpe.br high-pressure centers, and jet streams, as well as their energetics.

The detection of long-term trends in these regional systems is limited by the availability of reliable observations of atmospheric and oceanic parameters on global and regional scales. In general, reliable observations for the tropical region are available from groundand space-based platforms for just the last 30 years. Moreover, trends observed in regional systems, which are highly influenced by atmospheric and oceanic coupling, may capture information about the long-term oscillations of the systems instead of a real trend. Furthermore, reliable observations of natural drivers of the atmospheric-oceanic system, such as the total and spectral solar irradiances, are also limited to the last few decades (Vieira and Solanki 2010). Thus, we take into account these caveats when discussing any trend detected in the reanalysis products. 
The variability and structure of the tropical atmosphere regulate the weather and climate on global and regional scales (Zhang and Song 2006). The convergence of southeasterly trade winds in the Southern Hemisphere and the northeasterly trade winds in the Northern Hemisphere results in the formation of the ITCZ, which can be clearly seen on satellite images as a band of convective clouds encircling the globe near the equator. The ITCZ is responsible for the precipitation over Africa, the Americas, and Asia (e.g., Hastenrath and Heller 1977; Lamb 1978; Moura and Shukla 1981). Many disturbances such as easterly waves and convective clusters that affect the weather of the northern and northeastern coastal regions of South America (SA) are associated with the Atlantic ITCZ (Uvo and Nobre 1989a). Many studies (Nobre and Shukla 1996; Uvo and Nobre 1989b; Wang and Magnusdottir 2005) showed that this system influences the weather and climate of the northeastern region of Brazil (NEB), especially increasing the precipitation when it is situated in a southerly position and decreasing when it occupies a northerly position. That is, the variations in the ITCZ intensity and position are closely related to weather disturbances in the tropics of SA. The ITCZ follows the seasonal variability of the tropical circulation. During the boreal summer, the ITCZ migrates north, reaching approximately $8^{\circ} \mathrm{N}$, while its most southerly position is observed in April $\left(\sim 1^{\circ} \mathrm{N}\right)$ (Hastenrath and Heller 1977).

Another important aspect is the reduction of the horizontal pressure gradient across the Pacific Ocean in the last 50 years as observed in ship-based measurements and in the National Centers for Environmental Prediction (NCEP)-National Center for Atmospheric Research (NCAR) and the European Centre for Medium-Range Weather Forecasts (ECMWF) reanalyses. This reduction is consistent with simulations from general circulation models (GCMs) when sea surface temperatures (SSTs) are uniformly increased, according to Zhang and Song (2006).

The evolution of the upper- and middle-atmospheric composition and thermal structure may play an important role in determining the evolution of atmospheric circulation in the tropics and subtropics. According to Shindell et al. (2004), the dynamic response of the lower atmosphere to large volcanic eruptions appears to be a clear indication of a significant role of stratospheric perturbations in surface-level climate. Stenchikov et al. (2009) show that Atlantic meridional circulation is strongly influenced by volcanic emissions on a decadal time scale.

In the present study, we focus on the evolution of the Lorenz energy cycle (Lorenz 1955) in the ITCZ in the South American sector of the Atlantic Ocean. We search for changes in kinetic and available potential energies, as well as energy conversions associated with barotropic and baroclinic processes. The area of interest in this study encompasses the ITCZ between the latitudes of $5^{\circ} \mathrm{S}$ and $10^{\circ} \mathrm{N}$ and longitudes of $50^{\circ} \mathrm{W}$ and $0^{\circ}$. As rainfall in the northern portions of NEB is modulated by the intensity of convective activity of the ITCZ, the energetics of the ITCZ region is a relevant topic of research for the Brazilian climate and its changes.

This paper is structured as follows. In section 2, we describe the computation of the energetics, the method adopted for the identification of the ITCZ region, and the spectral and trend analysis. The results are described in section 3 and the conclusions are given in section 4 .

\section{Data and methodology}

\section{a. Zonal and eddy components of kinetic and available potential energy}

The atmospheric energy cycle equations for limited areas as developed by Robertson and Smith (1983) in isobaric coordinates are given by

$$
\begin{aligned}
& \frac{\partial A_{Z}}{\partial t}=\left(K_{Z} \rightarrow A_{Z}\right)-\left(A_{Z} \rightarrow A_{E}\right)+\mathrm{BA}_{Z}+G_{Z} \\
& \frac{\partial A_{E}}{\partial t}=\left(A_{Z} \rightarrow A_{E}\right)-\left(A_{E} \rightarrow K_{E}\right)+\mathrm{BA}_{E}+G_{E} \\
& \frac{\partial K_{Z}}{\partial t}=\left(K_{E} \rightarrow K_{Z}\right)-\left(K_{Z} \rightarrow A_{Z}\right)+\mathrm{BK}_{Z}+\mathrm{B} \Phi_{Z}-D_{Z} \\
& \text { and } \\
& \frac{\partial K_{E}}{\partial t}=\left(A_{E} \rightarrow K_{E}\right)-\left(K_{E} \rightarrow K_{Z}\right)+\mathrm{BK}_{E}+\mathrm{B} \Phi_{E}-D_{E}
\end{aligned}
$$

where $A_{Z}$ and $A_{E}$ are the zonal and eddy components of available potential energy, respectively; $K_{Z}$ and $K_{E}$ are the zonal and eddy components of kinetic energy, respectively; and $\mathrm{BA}_{Z}$ and $\mathrm{BA}_{E}$ are the transport of $A_{Z}$ and $A_{E}$ through the lateral boundaries of the limited area considered, respectively. Similar meanings are given to $\mathrm{BK}_{Z}$ and $\mathrm{BK}_{E}$. Furthermore, $G_{Z}$ and $G_{E}$ are generation terms of $A_{Z}$ and $A_{E}$, respectively; $\mathrm{B} \Phi_{Z}$ and $\mathrm{B} \Phi_{E}$ are the works realized at the boundaries by the zonal and eddy components of pressure, respectively; and $D_{Z}$ and $D_{E}$ are the dissipation rates of the kinetic energy components.

In the present study, we focus only on the energy components and their exchanges. The expressions for the energy components are 


$$
\begin{aligned}
& A_{Z}=\int_{p_{1}}^{p_{2}} \frac{\left[\left([T]_{\lambda}\right)_{\varphi}^{2}\right]_{\lambda \varphi}}{2[\sigma]_{\lambda \varphi}} d p, \\
& A_{E}=\int_{p_{1}}^{p_{2}} \frac{\left[(T)_{\lambda}^{2}\right]_{\lambda \varphi}}{2[\sigma]_{\lambda \varphi}} d p, \\
& K_{Z}=\frac{1}{2 g} \int_{p_{1}}^{p_{2}}\left[[u]_{\lambda}^{2}+[v]_{\lambda}^{2}\right]_{\lambda \varphi} d p, \text { and } \\
& K_{E}=\frac{1}{2 g} \int_{p_{1}}^{p_{2}}\left[(u)_{\lambda}^{2}+(v)_{\lambda}^{2}\right]_{\lambda \varphi} d p .
\end{aligned}
$$

The integrations in Eqs. (5)-(8) are performed for the layer between the pressure levels $p_{1}$ and $p_{2}$. Here, $T$ is the air temperature, $g$ is the acceleration of gravity, and $u$ and $v$ are the zonal and meridional components of wind. The static stability parameter for a limited area is $\sigma$ and given by

$$
[\sigma]_{\lambda \varphi}=g\left[\frac{T}{C_{p}}-\frac{p}{R} \frac{\partial T}{\partial p}\right]_{\lambda \varphi},
$$

where $C_{p}$ is the specific heat at constant pressure and $R$ is the gas constant for dry air. The square brackets with suffixes $\varphi$ and $\lambda$ signify the latitudinal and longitudinal means over the limited area considered. For details, refer to Reiter (1969). It is important to remember that by zonal components of energy we mean the energy contained in the zonally averaged flow. The energy conversions are given by

$$
\begin{aligned}
\left(K_{Z} \rightarrow A_{Z}\right)= & -\int_{p_{1}}^{p_{2}}\left[\left([T]_{\lambda}\right)_{\varphi}\left([\omega]_{\lambda}\right)_{\varphi}\right]_{\lambda \varphi} \frac{R}{g p} d p, \\
\left(A_{E} \rightarrow K_{E}\right)= & -\int_{p_{1}}^{p_{2}}\left[(T)_{\lambda}(\omega)_{\lambda}\right]_{\lambda \varphi} \frac{R}{g p} d p \\
\left(A_{Z} \rightarrow A_{E}\right)= & \left.-\int_{p_{1}}^{p_{2}}\left(\left[\frac{(T)_{\lambda}(v)_{\lambda}}{2[\sigma]_{\lambda \varphi} r} \frac{\partial\left([T]_{\lambda}\right) \varphi}{\partial \varphi}\right]_{\lambda \varphi}+\left[\frac{(T)_{\lambda}(\omega)_{\lambda}}{p^{R / C_{p}}} \frac{\partial}{\partial p}\left(\frac{\left([T]_{\lambda}\right)_{\varphi} p^{R / C_{p}}}{[\sigma]_{\lambda \varphi}}\right)\right]\right]_{\lambda \varphi}\right) d p, \quad \text { and } \\
\left(K_{E} \rightarrow K_{Z}\right)= & \frac{1}{g} \int_{p_{1}}^{p_{2}}\left(\left[\frac{\cos \varphi}{r}(u)_{\lambda}(v)_{\lambda} \frac{\partial}{\partial \varphi}\left(\frac{[u]_{\lambda}}{\cos \varphi}\right)\right]_{\lambda \varphi}+\left[\frac{(v)_{\lambda}^{2}}{r} \frac{\partial}{\partial \varphi}[v]_{\lambda}\right]_{\lambda \varphi}+\left[\frac{\tan \varphi}{r}(u)_{\lambda}^{2}[v]_{\lambda}\right]_{\lambda \varphi}\right. \\
& \left.+\left[(\omega)_{\lambda}(u)_{\lambda} \frac{\partial}{\partial p}[u]_{\lambda}\right]_{\lambda \varphi}+\left[(\omega)_{\lambda}(v)_{\lambda} \frac{\partial}{\partial p}[v]_{\lambda}\right]_{\lambda \varphi}\right) d p,
\end{aligned}
$$

where $\omega$ is the vertical velocity $\left(\mathrm{Pa} \mathrm{s}^{-1}\right)$.

The generation terms $G_{Z}$ and $G_{E}$ are given by

$$
\begin{aligned}
G_{Z} & =\int_{p 1}^{p 2} \frac{\left[\left([q]_{\lambda}\right)_{\varphi}\left([T]_{\lambda}\right)_{\varphi}\right]_{\lambda \varphi}}{C_{p}[\sigma]_{\lambda \varphi}} d p \quad \text { and } \\
G_{E} & =\int_{p_{1}}^{p_{2}} \frac{\left[(q)_{\lambda}(T)_{\lambda}\right]_{\lambda \varphi}}{C_{p}[\sigma]_{\lambda \varphi}} d p
\end{aligned}
$$

where $q=C_{p}(d T / d t)-\alpha \omega$ (Krishnamurti and Bounoua 1996; Ramirez Gutierrez et al. 2009) is a residual of the thermodynamic equation and therefore includes the convective heating, radiative heating, sensible heating, and also subgrid processes.

Note that $G_{E}$ here is mostly associated to latent heat release in the ITCZ and $(q)_{\lambda}(T)_{\lambda}$, which represents the generation because of condensation in the eddies resolved by the grid spacing of the dataset. Here, $G_{Z}$ is mainly caused by zonally averaged differential heating (i.e., warmer tropic receiving more energy and cooler extratropics receiving less energy). The release of latent heat on the large (or planetary) scale also generates $A_{Z}$. Moisture transported by the trade winds, on the global and regional scales, converges into the ITCZ region and heat is released through condensation, mainly in the middle and upper troposphere. ITCZ is made up of several cumulonimbus $(\mathrm{Cb})$ clusters where the release of latent heat is concentrated and the resulting heating contains a large eddy component mostly in the subgridscale eddies in which the conditional instability of the second kind (CISK) mechanism becomes important. The infrared role of cirrus in the ITCZ is more important than the short-wave effect. Below cirrus clouds, the radiative heating is very small, almost zero. In a region without cirrus clouds, the radiative cooling is significant and is partially responsible for the decay of part of $A_{E}$ and $A_{Z}$. 
(a)

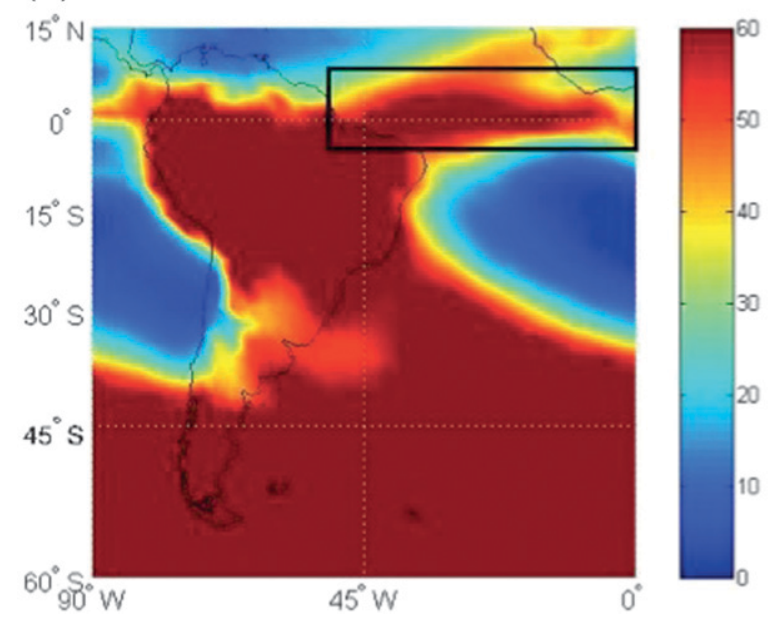

(b)

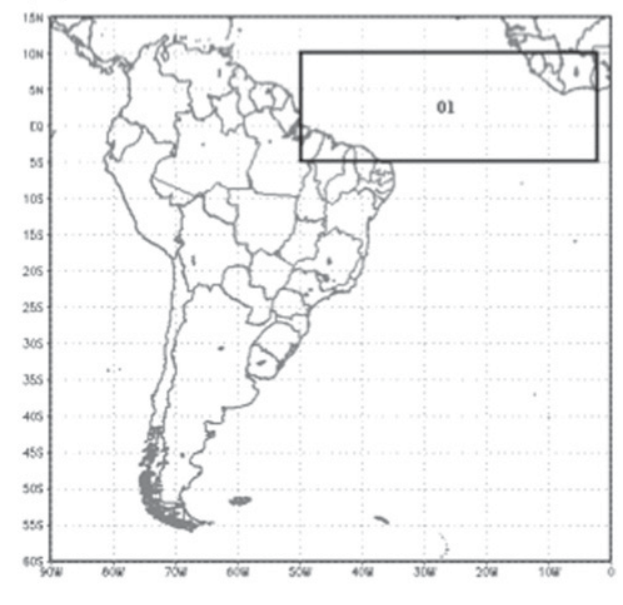

FIG. 1. (a) Distribution of the number of days during austral summer from 1979 to 2007 with OLR lower than $240 \mathrm{~W} \mathrm{~m}^{-2}$. Number of days per summer is indicated using the color code presented in the color bar on the right. (b) Black box indicates the ITCZ region over the Atlantic Ocean used to compute the Lorenz energy cycle.

\section{b. Datasets}

To evaluate the evolution of the energy components we used the NCEP-U.S. Department of Energy (DOE) Reanalysis II data, with a resolution of $2.5^{\circ}$ latitude $\times$ $2.5^{\circ}$ longitude. As the reanalysis data for the Southern Hemisphere is more reliable after 1979 (Kistler et al. 2001), we limited our analysis to the period between 1979 and 2007. Here, we employed daily fields of the zonal (i.e., $u$ ) and meridional (i.e., $v$ ) components of the wind, the omega (i.e., $\omega$ ) and the air temperature (i.e., $T$ ) for 17 levels from 1000 to $10 \mathrm{hPa}$, and the sea level pressure (SLP). The vertical integrations, however, were performed for $850-100 \mathrm{hPa}$. This lower limit is chosen in order to avoid the South American high mountains when computing, for example, the energetics for the South Atlantic convergence zone (SACZ).

National Oceanic and Atmospheric Administration (NOAA) Optimum Interpolation (OI), version 2, SST data from December 1981 to November 2009 are used to investigate the long-term evolution of SST in the ITCZ region. Monthly values are computed averaging the SST values for the ITCZ region defined in section $2 \mathrm{c}$.

A possible influence of the ENSO phenomenon on the variability of the ITCZ energy components is also investigated. For this, we employ the Southern Oscillation index (SOI) calculated from the monthly fluctuations in the surface pressure difference between Tahiti and Darwin by the Australian Bureau of Meteorology.

\section{c. Target area}

First, the region in which the Atlantic ITCZ is predominant needed to be identified. For this, we computed the climatology of the outgoing longwave radiation (OLR) for the austral summer (November-March) from 1979 to 2007 using the dataset from NOAA. Austral summer was chosen because during this period the ITCZ interacts most with other atmospheric systems over South America and the adjoining Atlantic, such as the uppertropospheric cyclonic vortex (UTCV) and the SACZ (Chaves and Cavalcanti 2001).

For each day in the 28-yr period, the OLR distribution was examined in the domain encompassing South America and the South Atlantic Ocean between $15^{\circ} \mathrm{N}$ and $60^{\circ} \mathrm{S}$, and $90^{\circ} \mathrm{W}$ and $0^{\circ}$. To identify the convective areas, we attribute either 0 or 1 to a variable $b$ depending on the OLR value: $b=1$ for OLR $\leq 240 \mathrm{~W} \mathrm{~m}^{-2}$ and $b=0$ for OLR $>240 \mathrm{~W} \mathrm{~m}^{-2}$. This threshold value is supposed to separate high (deep) convective regions from the others in the area of the ITCZ (Okoola 1998). Next, we compute the number of convective cloud cover days per summer $\mathrm{Nu}$ at the grid points (latitude and longitude):

$$
\mathrm{Nu}(\text { summer, lat, lon })=\sum_{i=1}^{N_{\text {days }}} b(\text { day, lat, lon }) .
$$

Figure 1 shows the distribution of $\mathrm{Nu}$ over South America and the adjoining Atlantic. In many parts of the region, we identify more than 60 days per summer of convective cloud cover by using the threshold value of $240 \mathrm{~W} \mathrm{~m}^{-2}$. From the figure, we can see that the demarked rectangular area encompasses the convective area and hence the ITCZ. This area $\left(5^{\circ} \mathrm{S}-10^{\circ} \mathrm{N}\right.$, $50^{\circ} \mathrm{W}-0^{\circ}$ ) is used to calculate the energetics on a daily basis for the period of study. 


\section{d. Spectral and trend analysis}

The temporal variability of the energetics is analyzed employing wavelet spectral analysis. The technique of spectral analysis employed is the discrete wavelet transform using the orthonormal Daubechies kernel of order 5 (i.e., db5). [See Daubechies (1992) for a comprehensive description of wavelet transform and its applications.] The orthonormal kernel employed here is composed of a mother and scaling functions. The convolution of the kernel with the time series decomposes the signal into orthonormal levels that provide spectral information about the evolution of the signal on different scales, in which the central frequency and bandwidth are determined by the mother and scaling functions (Daubechies 1992). This operation is equivalent to applying a bandpass filter. That is, the algorithm maintains periods/frequencies within a certain range and attenuates periods/frequencies outside that range. Here, the signal is decomposed in scales that are limited by powers of 2 . Furthermore, the orthonormal decomposition employed here allows us to detect trends in the time series as we separate the long- and short-term variations. In fact, this is an advantage of this method to analyze the spectra of time series over the Fourier transform method. We recognize that the Fourier transform should not be used to analyze nonstationary time series (i.e., time series whose statistical properties such as mean, variance, autocorrelation, etc., are not constant over time) as it assumes that the signal is stationary and that it extends to infinity.

We can write a given time series $S$ as

$$
S=\sum_{j \in Z} D_{j},
$$

where $D_{j}$ is the signal decomposition at level $j$ (i.e., the details at level $j$ ). As we are interested in investigating the long-term evolution of the parameters, it is convenient to distinguish the bands (details) with short and long periods. Considering a reference level $N$, we define the fine details as those associated with indices $j \leq N$, which correspond to scales between $2^{1}$ and $2^{N}$ (inclusive). The long-term variability is stored in details associated with indices $j>N$. In this way, we can group the latter into

$$
A_{N}=\sum_{j>N} D_{j}
$$

Consequently, the original signal can be reconstructed as a sum of the long-term trend $A_{N}$ and the short-period components stored in the details from levels $D_{1}$ to $D_{N}$. Here, the wavelet decomposition was performed up to level 11, which corresponds to periods longer than approximately 3072 days. The approximate central frequencies of the bandpass filter are presented in Table 1 . The
TABLE 1. Approximate central frequencies of the bandpass filter for energies ( $K_{Z}$ is zonal kinetic energy, $K_{E}$ is eddy kinetic energy, $A_{Z}$ is zonal available potential energy, and $A_{E}$ is eddy available potential energy).

\begin{tabular}{crrrrrr}
\hline \hline & Scale & $\begin{array}{c}\text { Period } \\
\text { (days) }\end{array}$ & $\begin{array}{c}K_{Z} \\
(\%)\end{array}$ & $\begin{array}{c}K_{E} \\
(\%)\end{array}$ & $\begin{array}{c}A_{Z} \\
(\%)\end{array}$ & $\begin{array}{c}A_{E} \\
(\%)\end{array}$ \\
\hline $\begin{array}{c}\text { Detail level } \\
1\end{array}$ & & & & & & \\
2 & 4 & 3 & 0.09 & 0.20 & 0.60 & 0.32 \\
3 & 8 & 12 & 0.34 & 0.62 & 0.97 & 0.57 \\
4 & 16 & 24 & 1.09 & 0.71 & 1.23 & 0.67 \\
5 & 32 & 48 & 1.37 & 0.79 & 1.07 & 0.57 \\
6 & 64 & 96 & 0.78 & 0.41 & 0.65 & 0.64 \\
7 & 128 & 192 & 1.65 & 0.52 & 1.05 & 0.77 \\
8 & 256 & 384 & 1.84 & 1.48 & 1.73 & 1.62 \\
9 & 512 & 768 & 0.36 & 0.17 & 0.34 & 0.20 \\
10 & 1024 & 1536 & 0.41 & 0.11 & 0.37 & 0.16 \\
11 & 2048 & 3072 & 0.11 & 0.18 & 0.12 & 0.08 \\
Approximation & & & & & & \\
level & & & & & & \\
11 & 2048 & $>3072$ & 91.24 & 93.83 & 90.81 & 94.07 \\
\hline
\end{tabular}

components of the energy cycle presented in Eqs. (5)-(8) and their transformation presented in Eqs. (10)-(15) are decomposed using the spectral analysis.

\section{Results}

\section{a. Energy components}

Figure 2 shows the daily values of the Lorenz energy cycle components computed from July 1979 to June 2007. Figures $2 \mathrm{a}$ and $2 \mathrm{~b}$ present the eddy and zonal kinetic energy components, while Figs. $2 \mathrm{c}$ and $2 \mathrm{~d}$ display the eddy and zonal available potential energy components. To provide a better visualization, the scales of the kinetic and potential energy components were set to different values on the $y$ axis. Note that $K_{Z}$ presents higher values and a higher variability than the other components; $A_{Z}$ stores a small fraction of the energy. The potential energy components are an order of magnitude less than the kinetic energy components. This is understandable because in the equatorial regions the horizontal thermal gradients are very small. However, the annual cycle is noticeable in all the components of energy. Short-term variations including intraseasonal variability are superimposed on the annual variability (extension of the graphs, not presented here, show short-term variability). Although small in general, $A_{E}$ peaks in austral summer, indicating that the perturbations in this season present thermal gradients larger than the zonally averaged meridional thermal gradients indicated by $A_{Z}$. The scales of the perturbations that contribute to the eddy components of energy are determined by the resolution of the datasets. Because of 

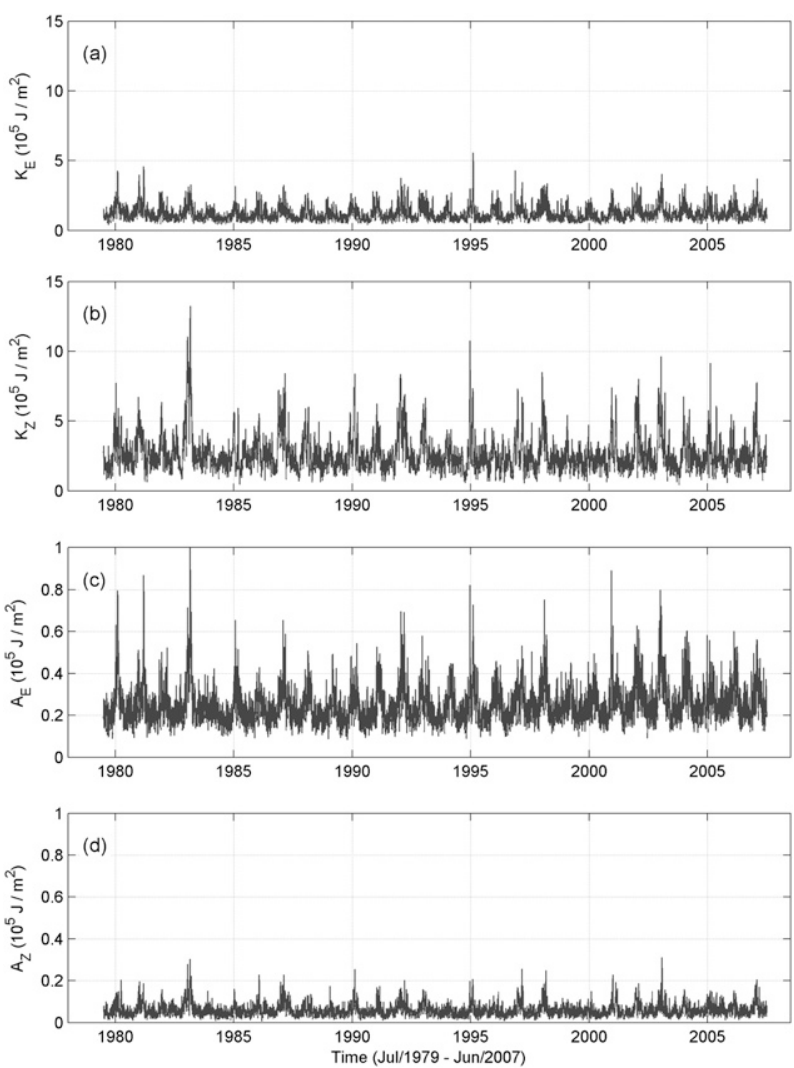

FIG. 2. Daily values of the Lorenz cycle energy components computed from NCEP-DOE reanalysis data from July 1979 to June 2007: (a) eddy kinetic energy, (b) zonal kinetic energy, (c) eddy potential energy, and (d) zonal potential energy.

the high shorter-term variability, long-term trends are not clearly detected by visual inspection of the graphs.

\section{b. Energy conversions and generation}

Figure 3 displays daily values of the energy conversions for the period of study. All the conversions are of the same order of magnitude except $A_{Z}-A_{E}$, which is one order of magnitude smaller. This is because the thermal gradients are very small in the ITCZ. It is important to note that the $A_{E}-K_{E}$ interaction is almost of the same order of magnitude as $K_{E}-K_{Z}$. This is because the perturbations in the ITCZ present intense upward and downward motions and, even if the temperature perturbations are small, the covariance between the perturbation of the vertical motion and the perturbation of the temperature is sufficiently high. In the extratropics, the conversions $A_{Z}-A_{E}$ and $A_{E}-K_{E}$ dominate, showing the importance of the baroclinic instability mechanism. In the equatorial regions, the conversion $K_{E}-K_{Z}$ is equally strong, indicating the importance of the barotropic instability mechanism for the kinetic energy of eddies in agreement with Mishra et al. (2007).
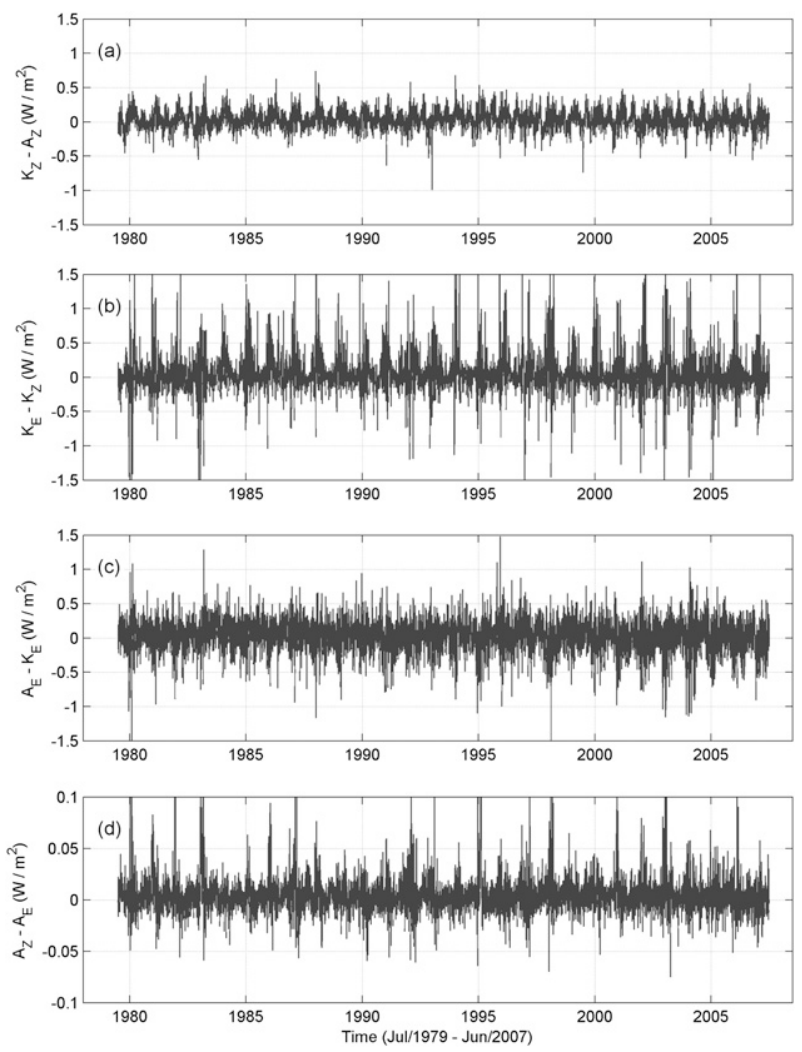

FIG. 3. Daily values of the Lorenz cycle energy conversion components computed from NCEP-DOE reanalysis data from July 1979 to June 2007: (a) $K_{Z}-A_{Z}$, (b) $K_{E}-K_{Z}$, (c) $A_{E}-K_{E}$, and (d) $A_{Z}-A_{E}$ energy conversions.

However, it is important to highlight that the result of Mishra et al. was for a tropical cutoff low. The values of the conversion $K_{Z}-A_{Z}$ are somewhat weaker, showing that overturning in the meridional plane is not as important as overturning in eddies represented by $A_{E}-K_{E}$. Figure 4 shows the daily values of the generation terms $G_{Z}$ and $G_{E}$. The generation terms are of the same order of magnitude as the conversion terms, except for the conversion $A_{Z}-A_{E}$. On the scale of days, the generation of $G_{E}$ is more important than $G_{Z}$ in the equatorial region considered, showing the importance of eddies.

\section{c. Distributions of daily values}

Figures 5a-d show the frequency distributions of the daily values of the energy components and their mean, median, and standard deviation values in the period of study. We can see that $K_{E}$ is less than $50 \%$ of $K_{Z}$, which has a mean value of $2.54 \times 10^{5} \mathrm{~J} \mathrm{~m}^{-2}$. This is another characteristic of equatorial atmospheric flows, where the wind perturbations are smaller than the largely steady zonal wind from east to west. The relative insignificance of the potential energy components (Figs. 2c,d) in 

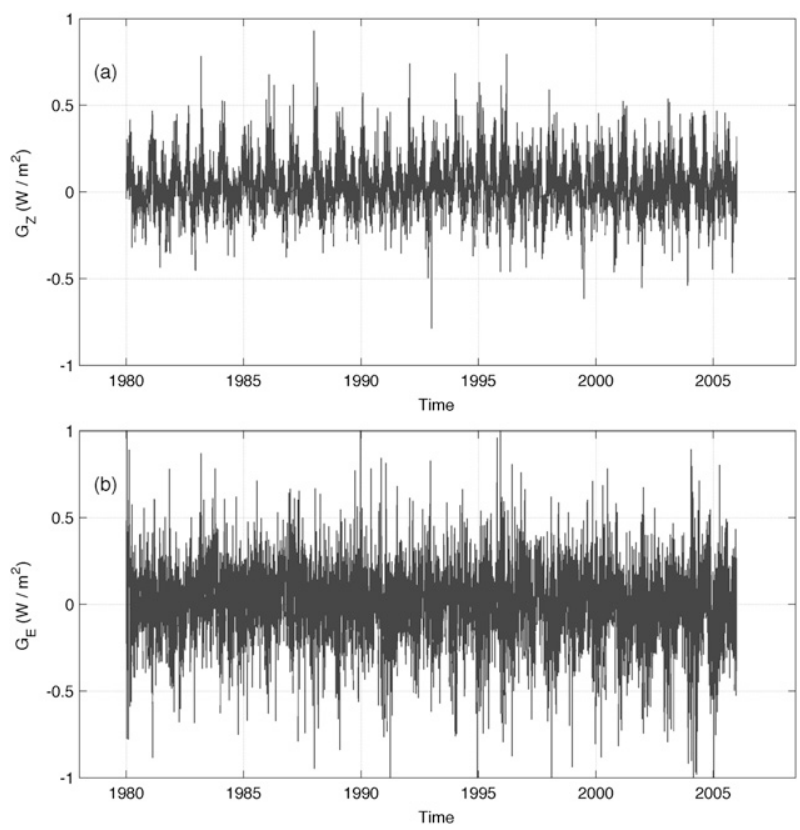

FIG. 4. Daily values of the generation terms of potential energy computed from NCEP-DOE reanalysis data from July 1980 to June 2006. (a) Generation of zonal potential energy (i.e., $G_{Z}$ ). (b) Generation of eddy potential energy (i.e., $G_{E}$ ).

comparison with the kinetic energy components can be seen more clearly in Figs. 5c and 5d. One important aspect is the long tail of the $K_{Z}$ distribution attaining values larger than $7.0 \times 10^{5} \mathrm{~J} \mathrm{~m}^{-2}$ (Fig. 5a). This means that occasionally the westerly wind (between 850 and $100 \mathrm{hPa}$ ) in the ITCZ target area can grow stronger. This variability may have implications for the intensity of transport of moisture into the South American tropics. The mean $A_{E}$ is 4 times larger than $A_{Z}$, meaning that when ITCZ is perturbed by smaller-scale disturbances, some temperature gradients develop.

Figures $5 \mathrm{e}-\mathrm{h}$ show the frequency distribution of the daily values of the energy conversions. We notice symmetry of the frequency distributions of the conversions about its zero value, especially in $K_{E}-K_{Z}$. That is, the conversions are equally likely to occur in one direction or the other on the day-to-day scale. In terms of the standard deviation, $K_{E}-K_{Z}$ and $A_{E}-K_{E}$ have similar values. Larger values of $K_{E}-K_{Z}$ relative to $A_{Z}-A_{E}$ indicate that the barotropic processes are more important than baroclinic processes. The $A_{Z}-A_{E}$ distribution shows that it is nearly zero most of the times. That is, baroclinic instability mechanisms are insignificant as is expected in the equatorial regions.

\section{d. Energy cycle in the Atlantic ITCZ}

Figure 6 shows the 28-yr mean complete energy cycle in the target area studied. First, we note that the available potential energies $A_{Z}$ and $A_{E}$ and their conversion are very weak relative to the global or hemispheric situation obtained by Oort and Peixoto (1974), as presented in Holton (2004), and $A_{E}$ is greater than $A_{Z}$. This is understandable as the meridional temperature differences in the narrow equatorial region are negligible. Another important difference is that the kinetic energy is much greater than the potential energy, in contrast to the hemispheric situation. However, surprisingly, the directions of conversions between energy types are the same as in the extratropics. The generation terms $G_{Z}$ and $G_{E}$ are caused by the heating of warmer regions and cooling of cooler regions. There is an infrared cooling at the top of cirrus clouds, but there is very little heating below the cirrus deck. What matters in $G_{E}$ is the vertical integration of this process. Meanwhile, $K_{E}$ is depleted by losing more energy to $K_{Z}$ than it receives from $A_{E}$. In Holton (2004) the frictional dissipation of $K_{E}$ is very high, which is not the case in our estimations. The discrepancy could be partly from errors in the model generated datasets and partly from the boundary effects [see Eqs. (1)-(4)]. This is mainly because our integrations did not include near-surface layers. There is an imbalance for $A_{E}$ and this may be from subgrid-scale processes, not included in the coarse datasets used.

\section{e. Spectral analysis and trend detection}

To distinguish the evolution of the energy components and conversions on different time scales, we decompose the signal on orthonormal levels using the procedure described in section 2 . The zonal component of kinetic energy is dominant during the period analyzed (not shown).

For comparing the signals observed in different bands, we employ the concept of time series energy (e.g., Rosso et al. 2006), which is linked to the Parseval's theorem. When applied to the Fourier theory, the interpretation is that the total energy contained in the waveform summed across the time domain is equal to the total energy of the waveform's Fourier transform summed across all of its frequency components. Similarly, as the wavelet kernel applied is orthonormal, the total waveform energy is equal to the wavelet transform summed across all levels. The percentage fraction of the time series energy contained in each band is presented in Table 1. Approximately $91 \%$ of the time series power is contained in long time scales (approximation level 11). This means that about $91 \%$ of the energy is constant or nearly constant and only $9 \%$ of the energy varies in time. The variability on the bands with central frequencies from 24 to 384 days accounts for approximately $6.7 \%$ of the time series energy. The annual variability is detected in the band $D_{8}$ (384 days), while the semiannual variability 

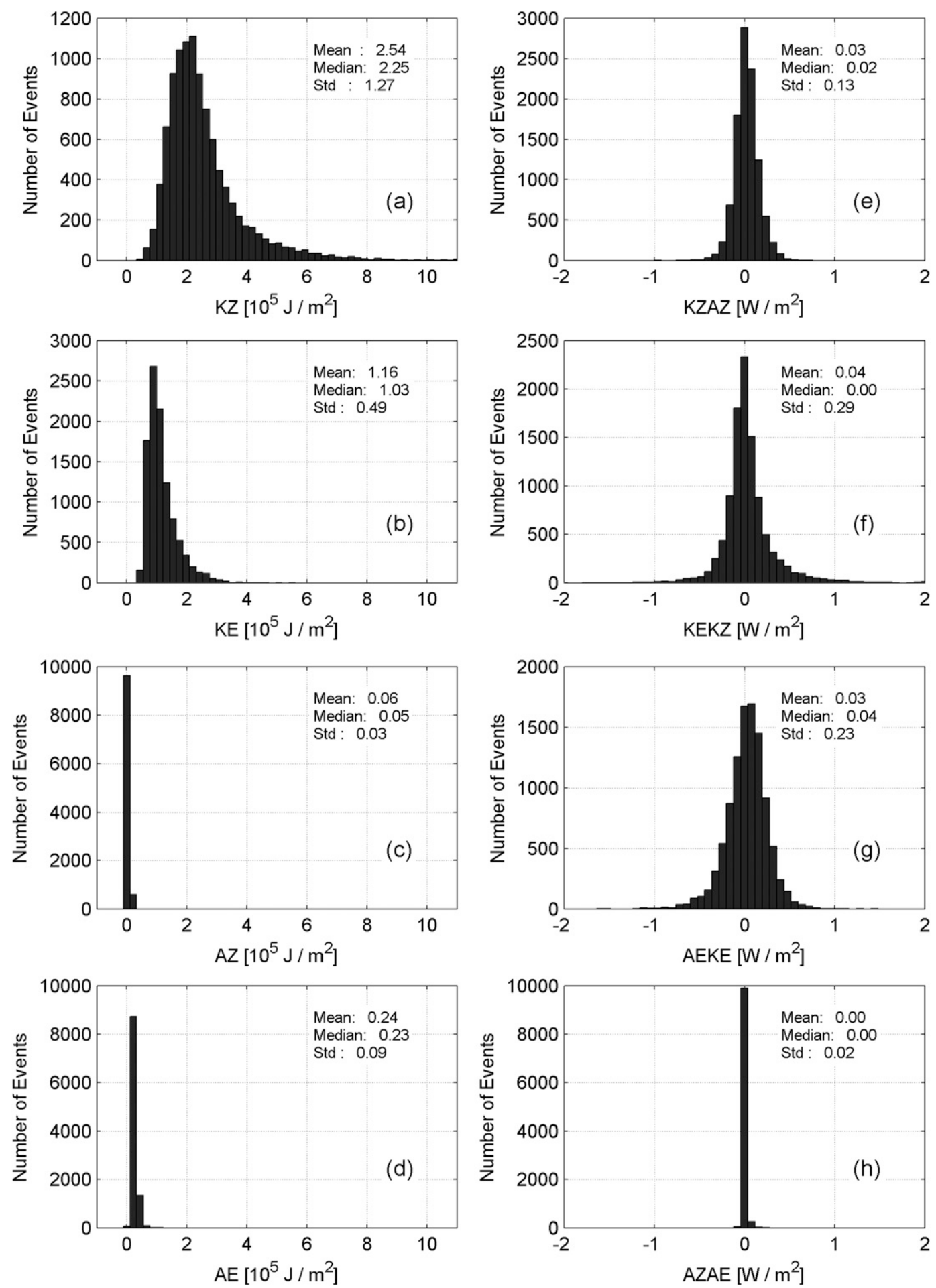

FIG. 5. Frequency distributions of the daily values of the Lorenz cycle energy components and conversions: (a) $K_{Z}$, (b) $K_{E}$, (c) $A_{Z}$, (d) $A_{E}$, (e) $K_{Z}-A_{Z}$, (f) $K_{E}-K_{Z}$, (g) $A_{E}-K_{E}$, and (h) $A_{Z}-A_{E}$. Mean, median, and standard deviation values are given in the respective panels. 


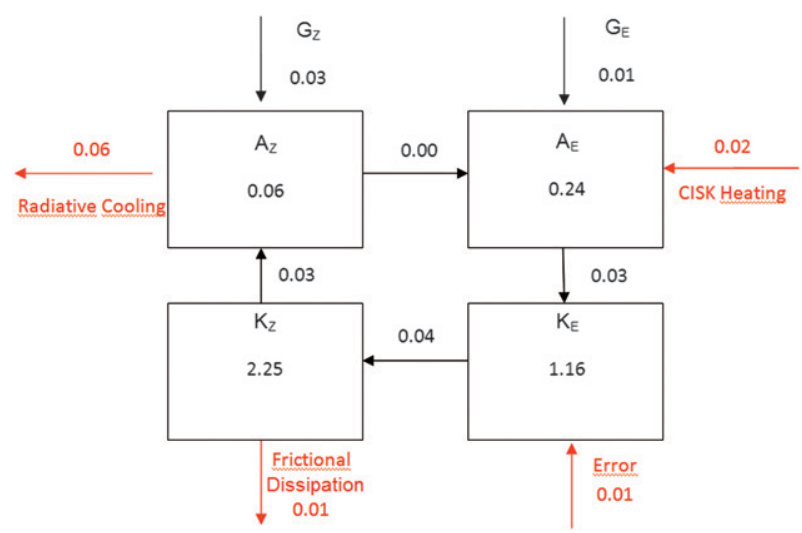

FIG. 6. A 28-yr mean energy cycle in the Atlantic ITCZ region ( $A_{Z}$ and $A_{E}$ are zonal and eddy available potential energies; $K_{Z}$ and $K_{E}$ are zonal and eddy kinetic energies; $G_{Z}$ is generation of $A_{Z}$ by meridional differential heating; $G_{E}$ is generation of $A_{E}$ ). Arrows indicate the direction of conversion of energy, generation, and dissipation. Quantities in boxes are in $10^{5} \mathrm{~J} \mathrm{~m}^{-2}$. Conversions, generations and dissipations are in watts per square meter. Numbers in black are calculated. Numbers in red are estimated.

is observed in the band $D_{7}$. We observe a strong annual cycle in all the components with high peaks in austral summer. The amplitude on the semiannual scale is also considerable and varies from component to component during the period analyzed. The strong signal observed around the 48-day periodicity corresponds to the Madden-Julian oscillation (Madden and Julian 1994).

For detecting long-term trends in the signal, we employ the reconstructions at level $A_{8}$, which incorporate spectral information of the levels with central periodicities longer than 768 days. In this way, the strong annual and semiannual variabilities are eliminated and longterm trends become evident. Figure 7 presents a comparison of the reconstructions at level $A_{8}$ for all energy components (black lines) from July 1979 to June 2007. Also shown are the trends (green lines) for the reconstructions at level $A_{8}$, whose equations are given in the respective panels. The scales are set differently for the kinetic and potential energy components, as potential energy components are much smaller than their kinetic energy counterparts. The zonal kinetic energy (i.e., $K_{Z}$ ) shows a steady linear trend of weakening. This means a gradual weakening of the westerly winds (between 850 and $100 \mathrm{hPa}$ ) in the Atlantic ITCZ region. Note that this trend is also observed at the lower troposphere (Tokinaga and Xie 2011). The reduction is about $17 \%$ since June 1978. This is similar to the reduction of the circulation in the tropical Pacific found by Zhang and Song (2006). While no appreciable trend is observed in $A_{Z}$, we also note small increases of $A_{E}$ and $K_{E}$. This may mean that the perturbations are strengthening. The vertical bars shown are \pm 1 standard deviation in the daily values of the energy components (see Saltzman and Fleisher 1960a,b). The standard deviations are larger than the annual means (running means), especially in the case of $K_{Z}$. Therefore, the trends observed in the annual mean values cannot be statically significant. However, the possibility of the presence of a secular trend superimposed on a large-amplitude short-range variability and several other longer-scale variabilities cannot be ignored.

The circulation in the ITCZ region is an integral part of the highly coupled atmosphere-ocean system. In this way, the trends identified in the energy components, although not very significant, should be consistent with trends of parameters indicating the state of the other components of the system. Here, we employ observations of the SST and SLP in the target area in order to evaluate the consistency of the trends observed, especially the reduction of zonal component of the kinetic energy (i.e., $K_{Z}$ ). To compare with the results presented in Fig. 7, we apply the wavelet decomposition to the time series of SST and SLP also.

Figure 8 presents the SST (Fig. 8a) and SLP (Fig. 8b). As in Fig. 7, the time series correspond to reconstructions at level 8. Therefore, the semiannual and annual variability were removed. A clear increase of the sea surface temperature and a reduction of the sea level pressure are observed during the last three decades. The increase of the SST is about $0.16^{\circ} \mathrm{C}$ decade $^{-1}$ while the reduction of the SLP is about $0.16 \mathrm{hPa}$ decade $^{-1}$. Increased SST may lead to increased convection, which decreases the surface pressure. Increased convection means increased $K_{E}$ and $A_{E}$, which perhaps decreases $K_{Z}$ somewhat. Thus, the trends in Fig. 8 seem to be consistent with each other and with Fig. 7a. The discussion presented here is only indicative because increased SST does not necessarily increase convection. However, for a given temperature gradient and stability condition, convection is more intense at higher temperatures, since in this case the atmosphere can hold and recycle larger amounts of moisture.

The values of the perceptual fraction of time series variance contained in each band for all energy conversions are presented in Table 2. As mentioned before, the mean daily values of the energy conversions are quasisymmetrically distributed around zero. Consequently, for the conversions $K_{E}-K_{Z}, A_{E}-K_{E}$, and $A_{Z}-A_{E}$ the reconstruction at level 11 contains just a small fraction of the signal, meaning that the variability of the energy conversions is mostly contained in the periodicities of a few days to approximately a decade. However, because of the lower variance of $K_{Z}-A_{Z}$ when compared 


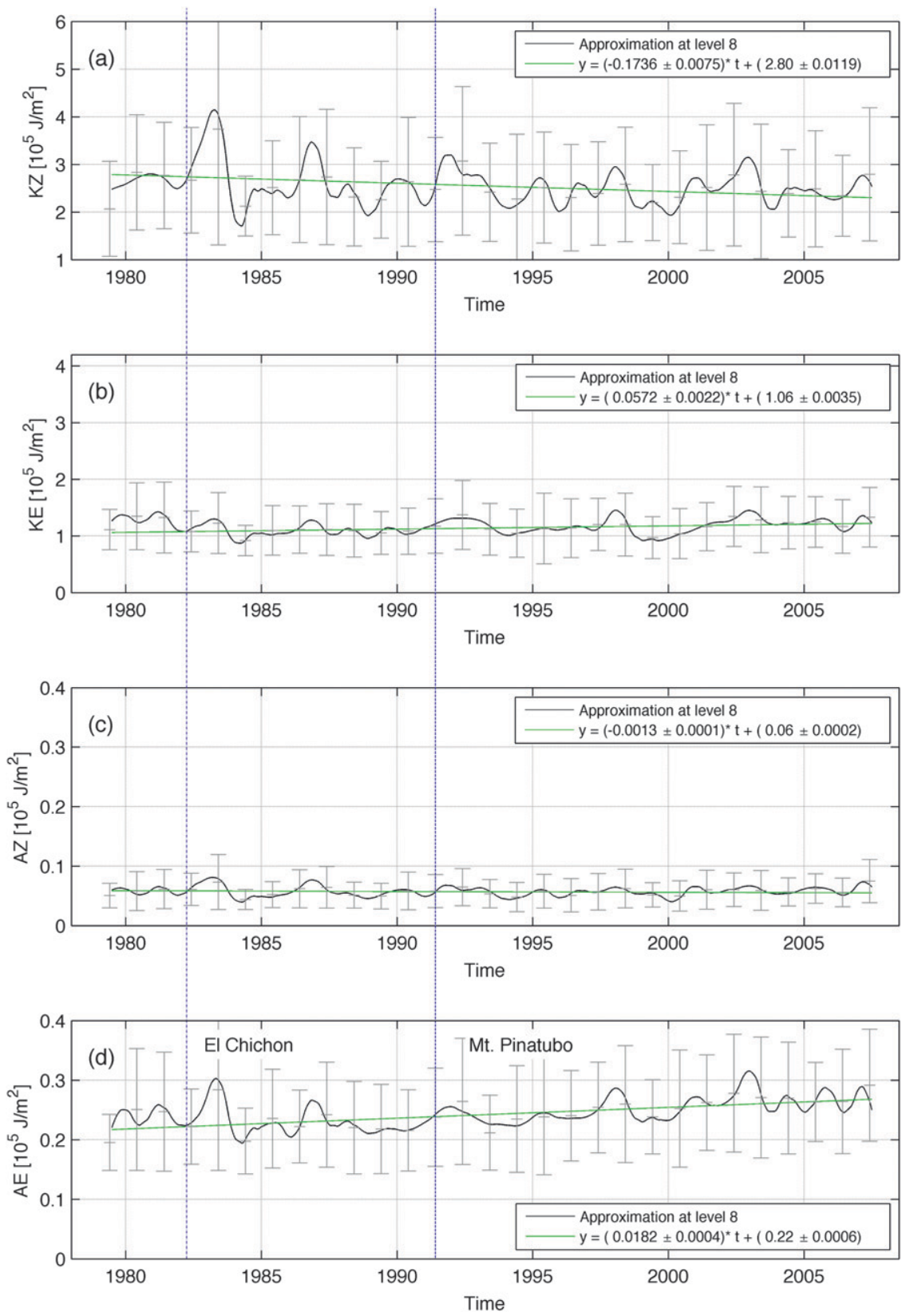

FIG. 7. Long-term trends in the Lorenz cycle energy components computed from NCEPDOE reanalysis data from July 1979 to June 2007: (a) zonal kinetic energy, (b) eddy kinetic energy, (c) zonal potential energy, and (d) eddy potential energy. Black lines present the reconstructions at level 8 (i.e., $A_{8}$ ) and green lines present the trend lines. Equations for the trend lines are shown in the respective panels. Time is presented in decades since 1 Jan 1979. Standard deviation (error) bars are shown in the panels for each year. The blue dashed lines indicate the El Chichón and Mt. Pinatubo eruptions, respectively.

with $K_{E}-K_{Z}$ and $A_{E}-K_{E}$, about $47.70 \%$ of the signal is observed at approximation level 11. The $K_{E}-K_{Z}$ conversion presents a peak at 12 days periodicity. That is, the barotropic process prefers this time scale. The $A_{E}-K_{E}$ peaks around 6 days periodicity and this is related to extratropical (or baroclinic) influence or frontal incursions into the ITCZ region (Thorncroft and Hodges 2001).

Although a great fraction of the signal of the wavelet decomposition for the $A_{E}-K_{E}$ energy conversion (not shown) is observed on time scales shorter than the annual variability, the semiannual and annual variability 

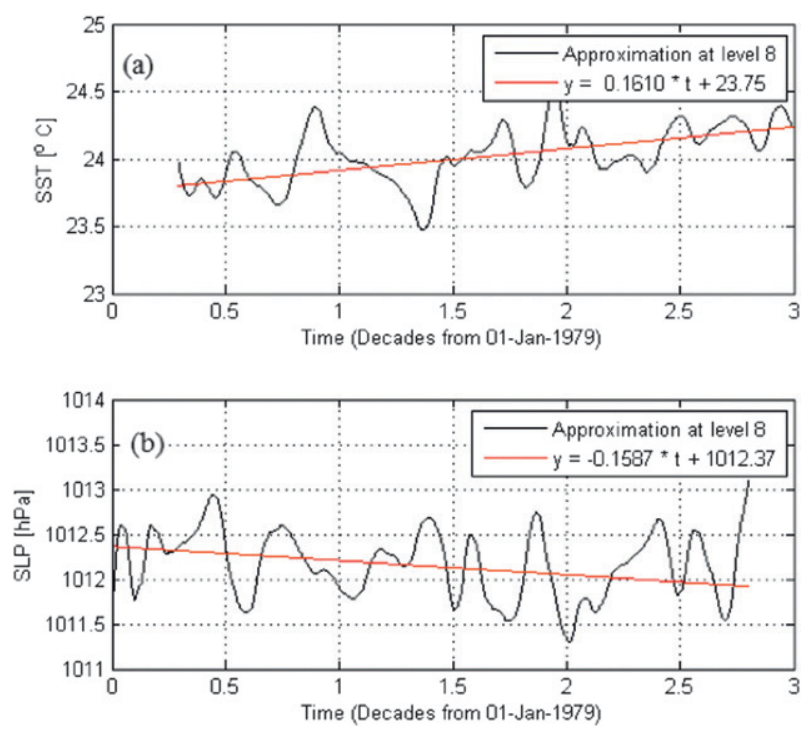

FIG. 8. (a) SST and (b) sea level pressure (SLP). The time series correspond to reconstructions at level 8 . Red lines present the linear trends. The corresponding equations are given in the respective panels. Time is presented in decades starting with 1 Jan 1979.

are observed at levels $D_{7}$ and $D_{8}$, respectively. The amplitude of the signal at these time scales is not uniform throughout the analyzed period. Figure 9 shows a comparison of the reconstructions of the energy conversion components at level 8, which are employed here to search for long-term trends in the time series. The trend lines and equations are also given in the respective panels. The energy conversion components do not present clear trends from 1978 to 2007. One exception is the $A_{E}-K_{E}$ conversion, which decreased about $3 \%$ in the analyzed period, indicating that baroclinic processes are weakening. At this reconstruction level, changes in the sign of the energy conversions are also noticeable. Changes in the sign of the energy conversion indicate changes in the maintenance processes inside the region studied. As expected, the standard deviations of the daily values, indicated by the vertical bars, are very large, because the day-to-day (or short range) variability is very large.

The $K_{E}-K_{Z}$ energy conversion is mostly caused by barotropic effects. The $K_{Z}-A_{Z}$ energy conversion is from lifting warmer air and descending cooler air in the zonal mean. Both conversions are cyclic with an approximate 2-yr periodicity; that is, one year the conversion, on the average, proceeds in one direction and the other year in the other direction. Slight positive mean values show that in the mean the region is barotropically stable. The nearly 2 -yr periodicity is akin to quasibiennial oscillation (QBO), which is strong in the lower stratosphere. However, this periodicity is present in the energy components (Fig. 7), as well as in their conversions (Fig. 9) in the equatorial Atlantic.
TABLE 2. Approximate central frequencies of the bandpass filter for conversion of energies $\left(K_{Z}-A_{Z}\right.$ is energy conversion between $K_{Z}$ and $A_{Z}, K_{E}-K_{Z}$ is energy conversion between $K_{E}$ and $K_{Z}, A_{E^{-}}$ $K_{E}$ is energy conversion between $A_{E}$ and $K_{E}$, and $A_{Z}-A_{E}$ is energy conversion between $A_{Z}$ and $A_{E}$ ).

\begin{tabular}{|c|c|c|c|c|c|c|}
\hline & Scale & $\begin{array}{r}\text { Period } \\
\text { (days) }\end{array}$ & $\begin{array}{c}K_{Z}-A_{Z} \\
\quad(\%)\end{array}$ & $\begin{array}{c}K_{E}-K_{Z} \\
\quad(\%)\end{array}$ & $\begin{array}{l}A_{E}-K_{E} \\
(\%)\end{array}$ & $\begin{array}{c}A_{Z}-A_{E} \\
\quad(\%)\end{array}$ \\
\hline \multicolumn{7}{|c|}{ Detail level } \\
\hline 1 & 2 & 3 & 8.20 & 8.12 & 18.78 & 13.23 \\
\hline 2 & 4 & 6 & 8.41 & 22.49 & 19.13 & 17.65 \\
\hline 3 & 8 & 12 & 7.37 & 23.66 & 14.77 & 16.91 \\
\hline 4 & 16 & 24 & 5.52 & 16.64 & 10.54 & 16.26 \\
\hline 5 & 32 & 48 & 3.91 & 9.52 & 5.83 & 8.12 \\
\hline 6 & 64 & 96 & 3.41 & 6.52 & 3.69 & 6.95 \\
\hline 7 & 128 & 192 & 8.12 & 2.93 & 4.80 & 7.10 \\
\hline 8 & 256 & 384 & 3.97 & 5.38 & 3.14 & 4.13 \\
\hline 9 & 512 & 768 & 1.07 & 1.35 & 1.46 & 1.90 \\
\hline 10 & 1024 & 1536 & 0.84 & 0.55 & 1.88 & 1.03 \\
\hline 11 & 2048 & 3072 & 1.48 & 0.17 & 1.23 & 0.64 \\
\hline \multicolumn{7}{|c|}{$\begin{array}{l}\text { Approximation } \\
\text { level }\end{array}$} \\
\hline 11 & 2048 & $>3072$ & 47.70 & 2.67 & 14.75 & 6.08 \\
\hline
\end{tabular}

Figure 10 presents the reconstruction of the generation terms. Here, $G_{E}$ shows a downward trend in the past three decades. In fact, average $G_{E}$ is negative in the last decade. Compared with Fig. $7 \mathrm{~d}$, we see that $A_{E}$ is strengthening while its generation $G_{E}$ from eddy heating is decreasing. Moreover, $A_{Z}-A_{E}$ does not show appreciable trend. This means that $A_{E}$ must have another source of energy that is not accounted for in the present calculations obtained by the coarse-resolution data. This mechanism could be CISK, which releases latent heat in the middle troposphere with the aid of large-scale moisture convergence.

\section{f. Comparison between SOI and $K_{Z}$}

The increase of $K_{Z}$ during the intense ENSO event (Fig. 7a) suggests the influence of the Pacific on the ITCZ in the Atlantic sector. Here, we investigate the relationship between the ENSO variability and $K_{Z}$. We just compare with this energy component because it presents the highest amplitude. To track the ENSO variability, we use the SOI as a proxy. Figures 11a and 11b show a comparison of the SOI and the $K_{Z}$ reconstructions at levels 8 and 9 , respectively. Note that the $K_{Z}$ scale is inverted. A reasonable correspondence between the time evolutions of the two series, at both levels, is noticeable. A reasonable correspondence of the time evolution of the time series at both levels is noticeable. At level 9 it is better. The coefficient of correlation increases from -0.56 to -0.60 from the reconstruction at level 8 to the one at level 9. The graphical agreement between SOI and $K_{Z}$ series of level 9 reconstructions is 


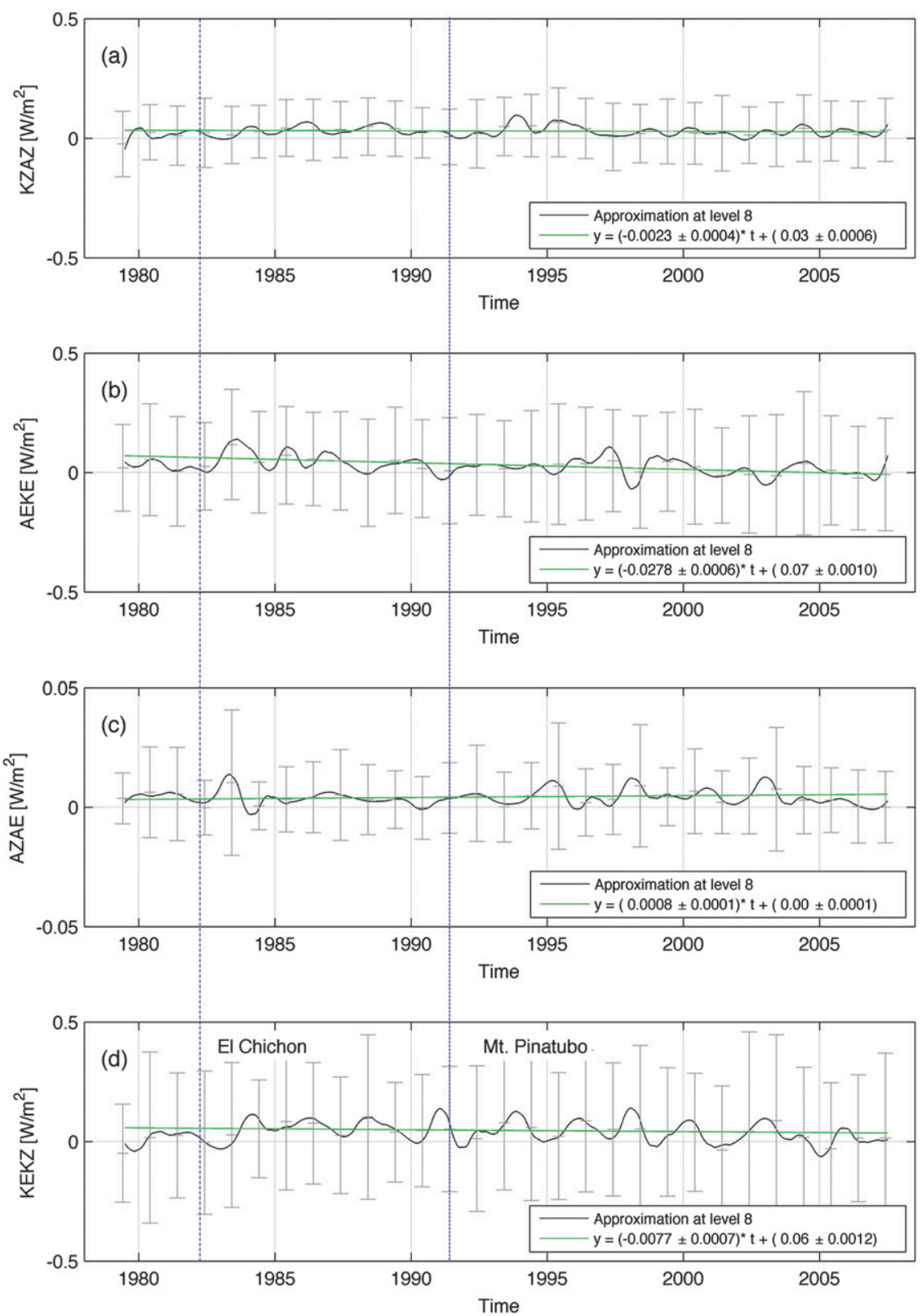

FIG. 9. Long-term trends of the Lorenz cycle energy conversion components computed from NCEP-DOE reanalysis data from July 1979 to June 2007: (a) $K_{Z}-A_{Z}$, (b) $A_{E}-K_{E}$, (c) $A_{Z}-A_{E}$, and (d) $K_{E}-K_{Z}$ energy conversions. The black lines present the reconstructions at level 8 (i.e., $A_{8}$ ) and the green lines present the trend lines. Equations for the trend lines are shown in the respective panels. Standard deviations (error) bars are shown in the panels for each year. The blue dashed lines indicate the El Chichón and Mt. Pinatubo eruptions, respectively.

rather remarkable, showing that ENSO exerts a large influence over the ITCZ in the South America and South Atlantic sector (Münnich and Neelin 2005; Janicot 1997). The trade winds in this region are stronger for low SOI values and are weaker for high SOI values. Although we considered winds from $850 \mathrm{hPa}$, not from the surface, the trade wind influence is present in the energy calculations.

\section{Summary and concluding remarks}

We have computed the Lorenz energy cycle for the intertropical convergence zone in the South American and Atlantic sector. The reanalyses datasets of winds and temperatures may contain large errors in the areas where the observational network is scanty. The ITCZ 


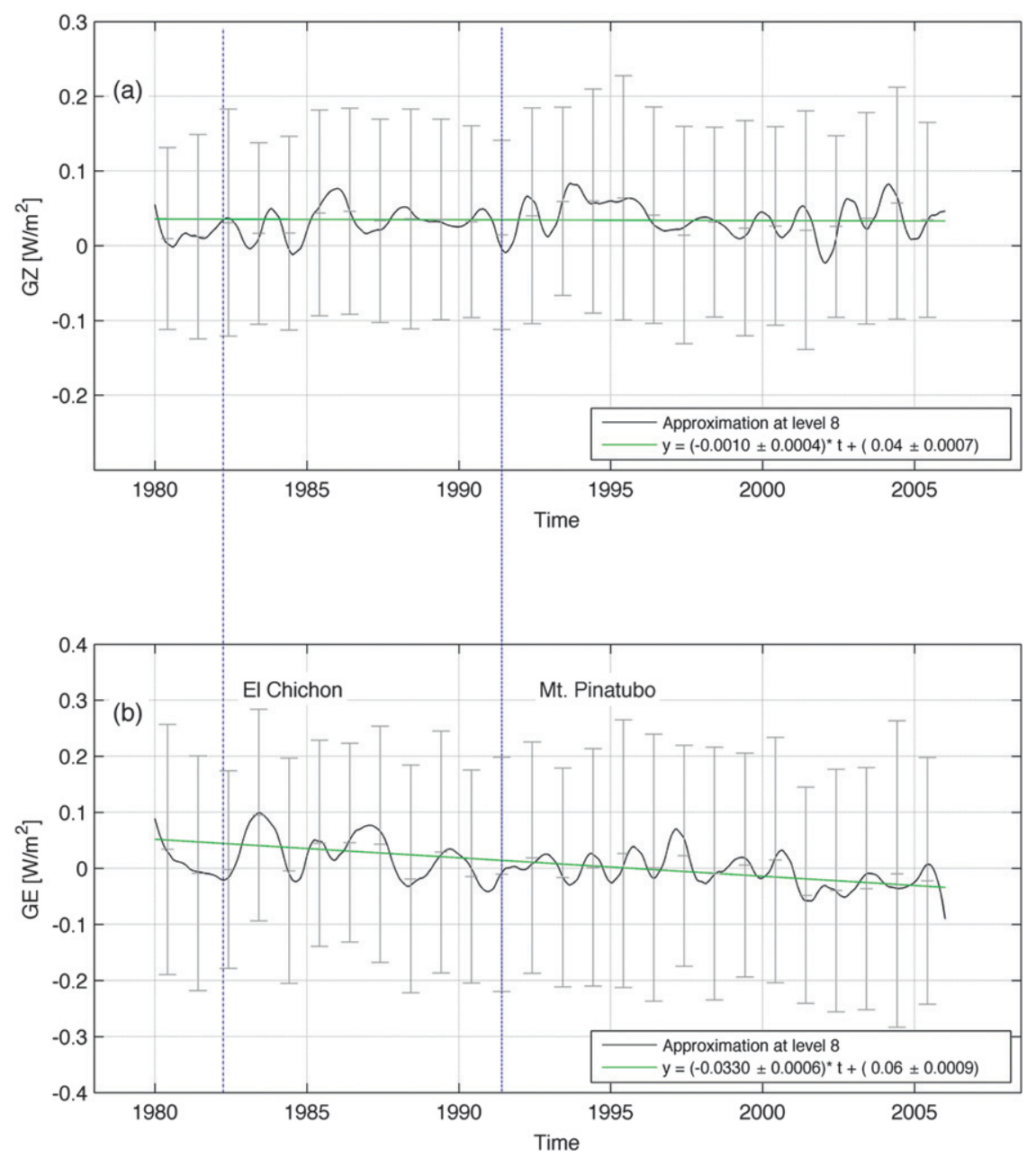

FIG. 10. Long-term trends of the generation terms of potential energy computed from NCEP-DOE reanalysis data from January 1979 to January 2006: (a) $G_{Z}$ and (b) $G_{E}$. The black lines present the reconstructions at level 8 (i.e., $A_{8}$ ) and the green lines present the trend lines. Equations for the trend lines are shown in the respective panels. Standard deviations (error) bars are shown in the panels for each year. The blue dashed lines indicate the El Chichón and Mt. Pinatubo eruptions, respectively.

region studied here is one such area. The calculations of the energy components involve covariances between atmospheric variables. For example, consider the zonal component of wind $u=\underline{u}+u_{e}$, where $\underline{u}$ is the true value and $u_{e}$ is the superimposed error, and $u_{e} \ll u$. The kinetic energy per unit mass is given by $1 / 2 u^{2}=1 / 2 \underline{u^{2}}+\underline{u} u_{e}+$ $1 / 2 u_{e}^{2}$. When integrated over a region, a latitude, or a time period, the last term, as a product of small values, may be neglected relative to the first. The middle term becomes a covariance between the true wind and its error. This term is small for randomly distributed errors, but can be large for systematic errors (e.g., if the error is large for large true wind or vice versa). Only when the errors in the datasets are normally distributed around the true values and are one order of magnitude less than the true values, the errors in the calculation of the energy components are negligible. That is, the errors in the datasets propagate into the energy calculations. The energy conversions involve triple products and the discussion of errors in their calculations becomes more involved. A satisfactory analysis of the errors in the reanalysis datasets and in the energy calculations is beyond the scope of this article. Notwithstanding the problems mentioned above, an analysis of the energetics of the Atlantic ITCZ region is attempted in this article and the main results are summarized below.

The zonal component of the kinetic energy (i.e., $K_{Z}$ ) presents a decreasing trend during the last 30 years, while the other energy components do not show significant changes. A concomitant increase of the sea surface 


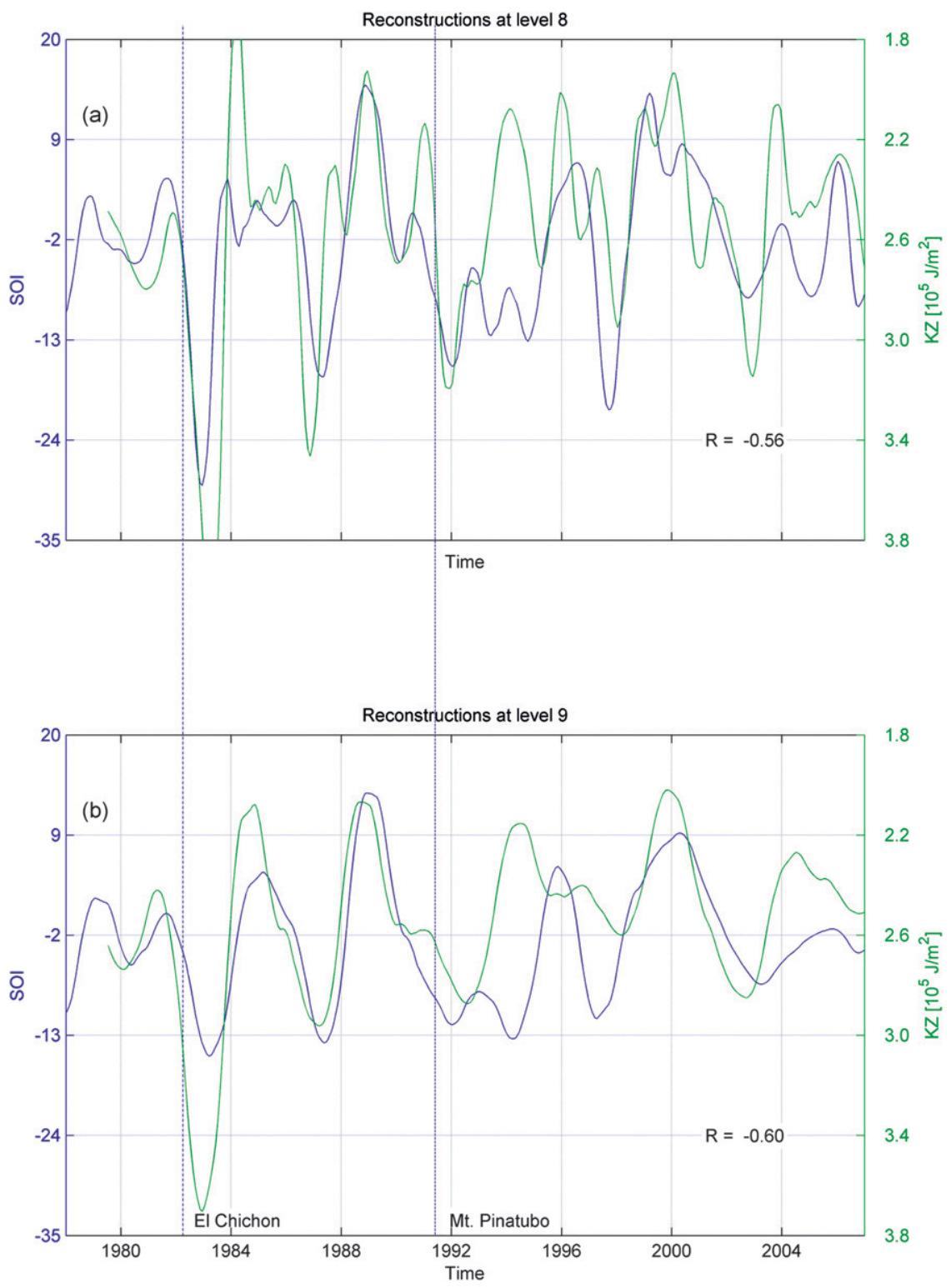

FIG. 11. Comparison of the SOI and the $K_{Z}$ reconstructions at levels (a) 8 and (b) 9 . The correlation coefficient is given in the panels.

temperature and a decrease of the sea level pressure are also observed in the same region. The decrease of $K_{Z}$ suggests a weakening of the trades in the ITCZ in the Atlantic sector. This may have important implications for the transport of water vapor from the Atlantic to the Amazon basin, a topic for future research.

The zonal component of the kinetic energy, compared with other energy components, presents the largest variability with values reaching up to $4 \times 10^{5} \mathrm{~J} \mathrm{~m}^{-2}$. The values of $K_{Z}$ and $A_{E}$ are significantly higher during the periods $1982 / 83$ and $1987 / 88$, indicating that the intense El Niño-Southern Oscillation (ENSO) events may have affected the ITCZ. In the 1982/83 period, the El Chichón eruption also might have affected the system. Several authors investigated the El Niño triggering and amplification by the El Chichón eruption, which was the largest of the century, injecting immense amounts of aerosols into the troposphere and stratosphere. The eruptions of the El Chichón volcano, which is located at $17.4^{\circ} \mathrm{N}$, $93.2^{\circ} \mathrm{W}$, occurred on $29 \mathrm{March}$ and 4 April 1982. Hirono (1988) proposed that tropospheric aerosols from the El Chichón eruption induced an atmospheric dynamic response producing a trade wind collapse. In addition, the trade wind reduction might have produced an 
oceanographic response which affected the timing and strength of the resulting El Niño. In our region of interest, both the observations and the mixed layer GCM suggest a decrease of the sea surface temperature after the eruptions (Shindell et al. 2004). In the same way, the changes in $K_{Z}$ and $A_{E}$ observed in 1982/83 seems to be related to the large El Niño event and to changes of atmospheric circulation in response to the presence of tropospheric and stratospheric aerosols released during the El Chichón eruption. The influence of volcanic eruptions on the trade wind intensity needs further investigation.

The agreement between the SOI and $K_{Z}$ in the Atlantic at levels 8 and 9 of the wavelet analyzed spectrum is remarkable, indicating a strong connection between the equatorial Pacific and the equatorial Atlantic. Also seen is a slight decrease of the $A_{E}-K_{E}$ energy conversion during the analyzed period. This trend indicates that the baroclinic processes are weakening. In the equatorial regions, the conversion $K_{E}-K_{Z}$ seems to be important, indicating that the mechanism responsible for the kinetic energy of eddies is the barotropic instability.

A larger fraction of the variability of the energy components is observed on time scales longer than the annual variability. For example, more than $90 \%$ of the time series energy of all components is recovered by the reconstructions at level 11 of the wavelet analysis. Most of this is constant mean energy. The semiannual and annual variabilities are also present at levels 7 and 8 , respectively. The synoptic variability is also observed in these components, but its contribution is relatively small.

Although $A_{Z}$ is several orders of magnitude smaller than $K_{Z}$, indicating that the zonally averaged thermal gradients are very feeble or absent, the perturbation available potential energy, $A_{E}$, is not so small relative to $K_{E}$. This indicates that the disturbances in the ITCZ region studied develop some temperature differences in the zonal direction.

The 28-yr mean energy cycle in the Atlantic ITCZ region is much weaker than the hemispheric cycle presented in Holton (2004). This is understandable because the thermal gradients are negligible there. However, the cycle of conversions follow the same direction as in the hemispheric case. The imbalances in the energy boxes are not large and they are mainly caused by boundary effects of the limited area considered. Moreover, the CISK mechanism and radiative effects at the top of the cumulus towers, not calculated in the present study, become important.

Acknowledgments. The NCEP Reanalysis data were provided by NOAA/Office of Oceanic and Atmospheric Research (OAR)/Earth System Research Laboratory
(ESRL)/Physical Sciences Division (PSD), Boulder, Colorado, USA, from their web site at http://www.cdc. noaa.gov/. The SOI was provided by the Australian Bureau of Meteorology from their web site at http:// www.bom.gov.au/climate/current/soi2.shtml. This work has been partially supported by the Brazilian National Council for Scientific and Technological Development [Conselho Nacional de Desenvolvimento Científico e Tecnológico (CNPq), projects 143004/2005-0, 200822/ 2010-1], and by The São Paulo Research Foundation (FAPESP, projects 2008/58161-1 and 2011/13976-0). The first author thanks the Dr. Luis Eduardo Vieira [Divisão de Geofísica Espacial (DGE) Instituto Nacional de Pesquisas Espaciais (INPE)] and Dr. Paulo Kubota [Centro Previsão de Tempo e Estudos Climáticos (CPTEC)/INPE] for technical support.

\section{REFERENCES}

Chaves, R. R., and I. F. A. Cavalcanti, 2001: Atmospheric circulation features associated with rainfall variability over southern Northeast Brazil. Mon. Wea. Rev., 129, 2614-2626.

Daubechies, I., 1992: Ten Lectures on Wavelets. Regional Conference Series in Applied Mathematics, Vol. 61, Cambridge University Press, 377 pp.

Hastenrath, S., and L. Heller, 1977: Dynamics of climatic hazards in Northeast Brazil. Quart. J. Roy. Meteor. Soc., 103, 77-92.

Hirono, M., 1988: On the trigger of El Niño Southern Oscillation by the forcing of early El Chichón volcanic aerosols. J. Geophys. Res., 93 (D5), 5365-5384.

Holton, J. R., 2004: An Introduction to Dynamic Meteorology. 4th ed. Elsevier, 529 pp.

Janicot, S., 1997: ENSO impact on atmospheric circulation and convection over the tropical Atlantic and West Africa. Ann. Geophys., 15, 471-475.

Kistler, R., and Coauthors, 2001: The NCEP-NCAR 50-Year Reanalysis: Monthly means CD-ROM and documentation. Bull. Amer. Meteor. Soc., 82, 247-267.

Krishnamurti, T. N., and L. Bounoua, 1996: An Introduction to Numerical Weather Prediction Techniques. CRC Press, 293 pp.

Lamb, P., 1978: Large-scale tropical Atlantic surface circulation patterns associated with sub-Saharan weather anomalies. Tellus, 30, 240-251.

Lorenz, E. N., 1955: Available potential energy and the maintenance of the general circulation. Tellus, 7, 157-167.

Madden, R. A., and P. R. Julian, 1994: Observations of the 4050-day tropical oscillation-A review. Mon. Wea. Rev., 122, 814-837.

Meehl, G. A., and Coauthors, 2007: Global climate projections. Climate Change 2007: The Physical Science Basis, S. Solomon et al., Eds., Cambridge University Press, 747-845.

Mishra, S. K., and Coauthors, 2007: Genesis of the Northeast Brazil upper-tropospheric cyclonic vortex: A primitive equation barotropic instability study. J. Atmos. Sci., 64, 1379-1392.

Moura, A. D., and J. Shukla, 1981: On the dynamics of droughts in Northeast Brazil: Observations, theory and numerical experiments with a general circulation model. J. Atmos. Sci., 38, 2653-2675.

Münnich, M., and J. D. Neelin, 2005: Seasonal influence of ENSO on the Atlantic ITCZ and equatorial South America. Geophys. Res. Lett., 32, L21709, doi:10.1029/2005GL023900. 
Nobre, P., and J. Shukla, 1996: Variations of sea surface temperature, wind stress, and rainfall over the tropical Atlantic and South America. J. Climate, 9, 2464-2479.

Okoola, R. E., 1998: Spatial evolutions of the active convective patterns across the equatorial eastern Africa region during Northern Hemisphere spring season using outgoing longwave radiation records. Meteor. Atmos. Phys., 66, 51-63.

Oort, A. H., and J. P. Peixoto, 1974: The annual cycle of the energetics of the atmosphere on a planetary scale. J. Geophys. Res., 79 (18), 2705-2719.

Ramirez Gutierrez, E., P. L. Silva Dias, J. A. Veiga, R. Camayo, and A. dos Santos, 2009: Multivariate analysis of the energy cycle of the South American rainy season. Int. J. Climatol., 29, 2256-2269, doi:10.1002/joc.1858.

Reiter, E. R., 1969: Mean and eddy motions in the atmosphere. Mon. Wea. Rev., 97, 200-204.

Robertson, F. R., and P. J. Smith, 1983: The impact of model moist processes on the energetics of extratropical cyclones. Mon Wea. Rev., 111, 723-744.

Rosso, O. A., and Coauthors, 2006: EEG analysis using waveletbased information tools. J. Neurosci. Methods, 153, 163-182.

Saltzman, B., and A. Fleisher, 1960a: The modes of release of available potential energy in the atmosphere. J. Geophys. Res., 65 (4), 1215-1222.

_ , and - 1960b: Spectrum of kinetic energy transfer due to large-scale horizontal Reynolds stresses. Tellus, 12, 110-111.

Shindell, D. T., G. A. Schmidt, M. E. Mann, and G. Faluvegi, 2004: Dynamic winter climate response to large tropical volcanic eruptions since 1600. J. Geophys. Res., 109, D05104, doi:10.1029/ 2003JD004151.

Stenchikov, G., T. L. Delworth, V. Ramaswamy, R. J. Stouffer, A. Wittenberg, and F. Zeng, 2009: Volcanic signals in oceans. J. Geophys. Res., 114, D16104, doi:10.1029/2008JD011673.

Thorncroft, C., and K. Hodges, 2001: African easterly wave variability and its relationship to Atlantic tropical cyclone activity. J. Climate, 14, 1166-1179.

Tokinaga, H., and S.-P. Xie, 2011: Weakening of the equatorial Atlantic cold tongue over the past six decades. Nat. Geosci., 4, 222-226, doi:10.1038/ngeo1078.

Uvo, C. R. B., and C. A. Nobre, 1989a: The intertropical convergence zone (ITCZ) and the precipitation on Northeast Brazil. Part I: The ITCZ position over the equatorial Atlantic. Climanálise, 4, 34-40.

$\longrightarrow$, and $-1989 \mathrm{~b}$ : The intertropical convergence zone (ITCZ) and the precipitation on Northeast Brazil. Part II: The influence of the equatorial Atlantic winds and SST. Climanálise, 4, 39-47.

Vieira, L. E. A., and S. K. Solanki, 2010: Evolution of the solar magnetic flux on time scales of years to millennia. Astron. Astrophys., 509, A100, doi:10.1051/0004-6361/200913276.

Wang, C. C., and G. Magnusdottir, 2005: ITCZ breakdown in three-dimensional flows. J. Atmos. Sci., 62, 1497-1512.

Zhang, M. H., and H. Song, 2006: Evidence of deceleration of atmospheric vertical overturning circulation over the tropical Pacific. Geophys. Res. Lett., 33, L12701, doi:10.1029/ 2006GL025942. 